\title{
Assessment of Phycoremediation Efficiency of Spirogyra Maxima by using Heavy Metals Manganese and Lead
}

\author{
Nimisha $\mathrm{P}^{1}$, Dr. Sincy Joseph ${ }^{2}$
}

\author{
${ }^{1}$ M.Sc. Botany, Nirmala College for Women, Coimbatore, India \\ ${ }^{2}$ Assistant Professor, Department of Botany, Nirmala College for Women, Coimbatore, India
}

\begin{abstract}
Heavy metals are non-degradable pollutants and must be removed or reduced to acceptable limits before discharging into the environment to avoid threats to living organisms. This study was carried out to assess Manganese and Lead removal efficiency of the Spirogyra maxima isolated from ponds. The heavy metal removal capacity of the algal species was investigated for the period of 30 days at room temperature $\left(28 \pm 2^{\circ} \mathrm{C}\right)$ and regular light. The percentage Manganese removal on day 30 by Spirogyra species was $76.81 \%$ and the percentage removal of the lead is above $90 \%$. In the present study, the capacities of live green algae, Spirogyra maxima were evaluated for toxic heavy metals, $\mathrm{Pb}, \mathrm{Mn}$ from water bodies. The study examines the possibility of using live Spirogyra to biologically remove aqueous Lead and Manganese of low concentration from waste water. These algae proved that efficient biological vectors for heavy metal uptake.
\end{abstract}

Keywords-Heavy metals, degradable, pollutants, phycoremediation, investigated, vectors, efficient.

\section{INTRODUCTION}

Heavy metals are one of the major threats to the environment and a serious problem due to their incremental accumulation in the food chain. Unlike most organic wastes and the microbial load in aquatic bodies, metal contaminants are not biodegradable, tending to accumulate in living organisms, thus they becoming a permanent burden on ecosystems (Bayo, 2012).Most of the heavy metals are transition elements with incompletely filled d-orbitals. These d-orbitals provide heavy metal cations with the capability to form complex and colored compounds. Trace amounts $\left(\mu \mathrm{gL}^{-}\right.$ ${ }^{1}$ ) of some metal ions such as copper, cobalt, iron, nickel are required by living organisms as cofactors for the enzymatic activities. On the other hand, heavy metal ion concentrations at ppm $\left(\mathrm{mgL}^{-1}\right)$ level are known to be toxic to the organisms because of irreversible inhibition of many enzymes by the heavy metal ions.

Discharge of industry effluents to the land of irrigation influences the physico-chemical properties of soil (Nagaraju and Rangaswami, 2007; Kumar and Chopra, 2010). The increasing amount of heavy metals has caused imbalance in aquatic ecosystems and the biota growing under such habitats accumulate high amounts of heavy metals $(\mathrm{Cu}$, $\mathrm{Zn}, \mathrm{Cd}, \mathrm{Cr}$ and $\mathrm{Ni}$ ) which are being assimilated and transferred within food chains by the process of magnification (Pergent et al., 1999; Kumar and Chopra, 2010). The release of industrial and municipal wastewater poses serious environmental challenges to the receiving water bodies (Yang et al., 2008). Water pollution occurs when pollutants like heavy metals and other contaminants are discharged directly or indirectly into the water bodies. The presence of polluting metals like $\mathrm{Pb}, \mathrm{Cd}, \mathrm{Cu}, \mathrm{Cr}, \mathrm{Fe}$ and $\mathrm{Zn}$ are very dangerous to human body. Non-essential heavy metals have directly or indirectly an adverse effect on biological activities of the living organisms. The presence of heavy metals in water degrades their quality which affects human health. Even the essential metals are at higher concentration is toxic to the living organisms. The livestock systems are prone to general problem of pollution originating from industrial activity. Excessive accumulation of $\mathrm{Pb}$ causes impaired kidney functions, multiple sclerosis, anaemia neurological diseases and encephalitis. Excess Cd leads to nephritis and wrong bone metabolism. Wilson's disease is 
caused by excess $\mathrm{Cu}$ and excess $\mathrm{Zn}$ causes the disease of metal fume fever.

Wastewater is usually rich in contaminants in the form of nutrients, heavy metals and hydrocarbons. The presence of nutrients especially nitrogen $(\mathrm{N})$ and phosphorus $(\mathrm{P})$, in the form of nitrate, nitrite, ammonia/ammonium or phosphorus in wastewater leads to eutrophication (Liu et al., 2010; Yang et al., 2008). Microalgae represent an integral part of the microbial diversity of wastewaters, which can also play a role in the self-purification of these wastewaters (Sen et al., 2013).

Phycoremediation refers to the technology of using algae for the remediation of wastes, predominantly in the treatment of wastewaters as a part of the secondary treatment (Dresback et al., 2001; Sen et al., 2013). The term 'phycoremediation' is in vogue for more than a decade, and of late the technology have begun to taste commercial success. A number of articles have been published on phycoremediation research and many authors have successfully established the fact that treatment of wastewaters using algae, microalgae in particular, leads to remarkable reduction of an array of organic and inorganic nutrients, including some of the toxic chemicals (Beneman et al., 1980; Gantar et al., 1991; de-Bashan et al., 2002; Queiroz et al., 2007; Thomas et al., 2016).

Microalgae offer a low-cost and effective approach to remove excess nutrients and other contaminants in tertiary wastewater treatment, while producing potentially valuable biomass, because of a high capacity for inorganic nutrient uptake (Bolan et al., 2004; Munoz and Guieyssea, 2006; Thomas et al., 2016). Using microalgae in continuous treatment processes would be of great advantage, because most industries are in dire exigency for implementing cost effective continuous treatment processes. Algal species are relatively easy to grow, adapt and manipulate within a laboratory setting and appear to be ideal organisms for use in remediation studies (Dubey et al., 2011; Sen et al., 2013). In addition, phycoremediation has advantages over other conventional physico-chemical methods, such as ion exchange, reverse osmosis, dialysis and electro-dialysis, membrane separation, activated carbon adsorption, and chemical reduction or oxidation, due to its better nutrient removal efficiency and the low cost of its implementation and maintenance (Dresback et al., 2001; Thomas et al., 2016).
Microalgae constitute a broad category of organisms encompassing photoautotrophic eukaryotic microalgae and prokaryotic cyanobacteria, which are distributed both in fresh and marine environments, with a wide range of diversity in their thallus organization and habitat (Lee, 2008). The biodiversity of microalgae is enormous and estimated to be about 200,000-800,000 species, out of which about 50,000 species are only described (Starckx, 2012). This enormous diversity and propensity to adapt to extreme and inhospitable habitats has led the scientific community to screen, identify promising strains / genera and develop promising microalgae-based technologies for wastewater treatment (Fouilland, 2012; Thomas et al., 2016). Spirogyra maxima are a member of the Algae. These are simple plants ranging from single-celled organisms (Chlamydomonas, Euglena) to complex seaweeds. They contain chlorophyll and make their food by photosynthesis (Sen et al., 2013).

Spirogyra is a filamentous alga. Its cells form long, thin strands that, in vast numbers, contribute to the familiar green, slimy 'blanket weed' in ponds. Thus the aim of the study was to investigate the performance of Spirogyra maxima in improvement of sugar mill effluent quality (Matagi et al., 1998; Dubey et al., 2011; Sen et al., 2013). Spirogyra maxima have many features that make them ideal candidates for the selective removal and concentration of heavy metals, which include high tolerance to heavy metals, ability to grow both autotrophically and heterotrophically, large surface area/volume ratios, phototaxy, phytochelatin expression and potential for genetic manipulation (Cai et al., 1995; Dubey et al., 2011; Elumalai et al., 2013; Thomas et al., 2016). Therefore, the present investigation was carried out to determine the phycoremediation potential of Spirogyra maxima by using heavy metals Manganese and Lead with the following objectives:

- To assess the phycoremediation efficiency of Spirogyra maxima.

- To analyze the potential use and its role in reduction of water pollution by heavy metals.

- To study the characteristics of the sample solution before and after phycoremediation.

- To analyze the removal efficiency of lead and manganese.

- To assess the change in $\mathrm{pH}$ of the sample solution before and after the phycoremediation. 


\section{MATERIALS AND METHODS}

\section{* COLLECTION OF THE SAMPLES}

Water samples with algae were collected from Lily pond inside the botany garden from the college campus.

\section{- PREPARATION OF HEAVY METAL SOLUTION}

Stock solution was prepared by dissolving $0.5 \mathrm{~g}$ potassium permanganate $\left(\mathrm{KMnO}_{4}\right)$ and $0.5 \mathrm{~g}$ lead acetate in deionized water, and shaked for 24hours to obtain complete dissolution. The initial Manganese and Lead concentrations and $\mathrm{pH}$ of each concentration are measured at the beginning of all experiment using Atomic Absorption Spectrophotometer (AAS) and a digital $\mathrm{pH}$ meter.

\section{* PHYCOREMEDIATION EXPERIMENTAL DESIGN}

After the preparation of the stock solutions poured in to the plastic trays.10g of algal culture was inoculated in to each plastic trays. Sample A contains Lead solution with $10 \mathrm{~g}$ of Spirogyra maxima. And Sample B contains Manganese solution with $10 \mathrm{~g}$ of Spirogyra maxima.

The initial concentration of the Manganese and Lead were taken on the day before phycoremediation and the final concentrations were taken after 30 days.

The percentage bioremoval efficiency of the algae was calculated using the formula:

$\%$ Removal $=\frac{C 1-C 2}{C 2} \times 100$

Where $\mathrm{C}_{1}=$ initial concentration

$$
\mathrm{C}_{2}=\text { final concentration }
$$

Freshly collected Spirogyra

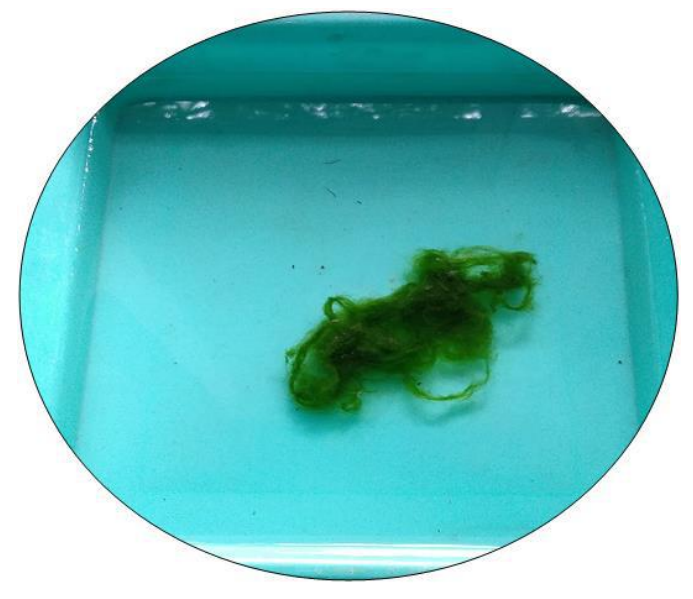

\section{Microscopic view of Spirogyra strains}

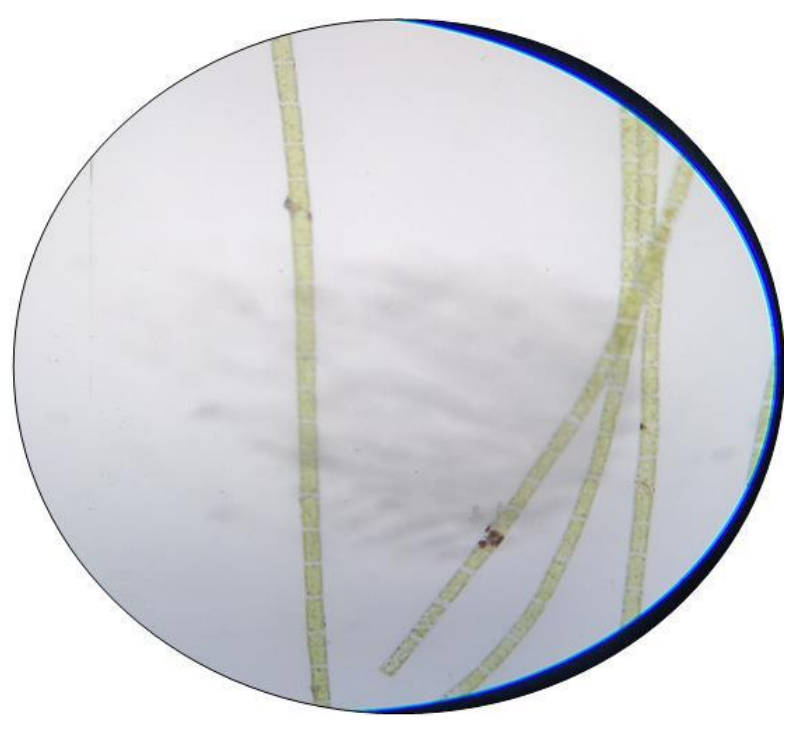

Algal culture in Mn (KMnO4) Solution

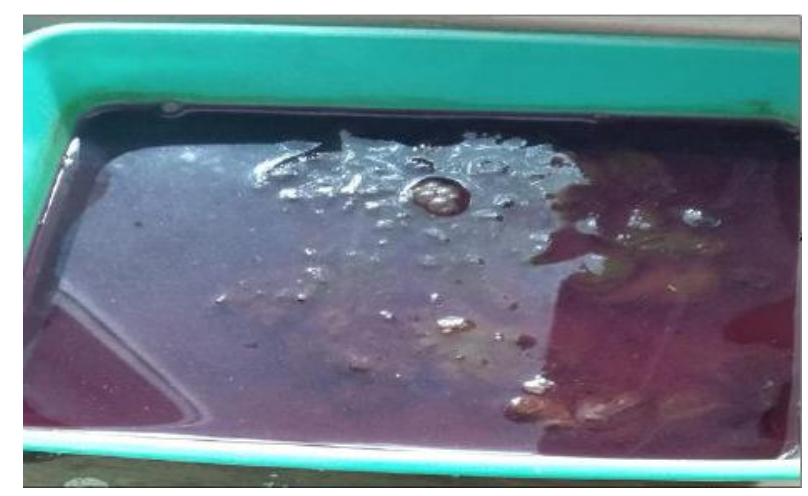

Algal culture in $\mathrm{Pb}\left(\mathrm{C}_{2} \mathrm{H}_{3} \mathrm{O}_{2}\right)_{2}$ Solution

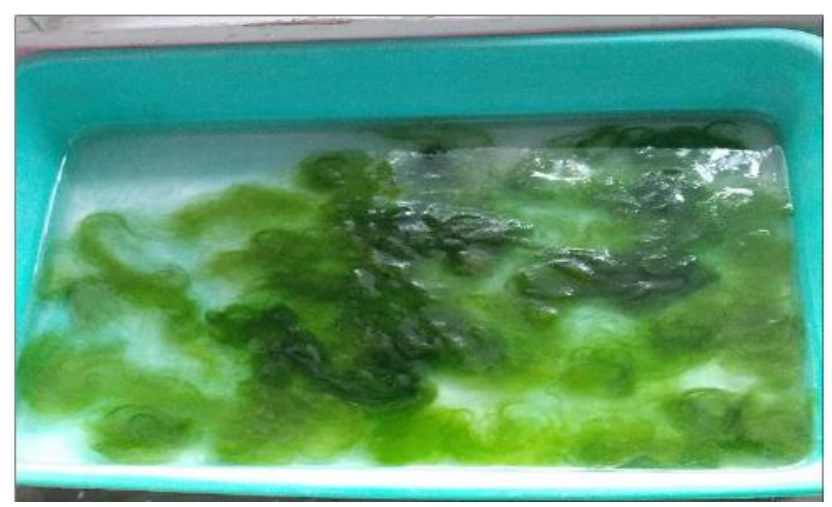




\section{RESULTS}

Table 1. Phycoremediation analysis of the sample solutions.

\begin{tabular}{|c|c|c|c|c|c|}
\hline \multirow{2}{*}{ PARAMETER } & \multicolumn{4}{|c|}{ Sample Analysis (mg/L) } \\
\cline { 2 - 6 } & $\begin{array}{c}\text { Before } \\
\text { phycoremediation } \\
(0 \text { days })\end{array}$ & $\begin{array}{c}\text { After } \\
\text { phycoremediation } \\
(30 \text { Days })\end{array}$ & $\begin{array}{c}\text { Removal } \\
\text { Efficiency } \\
(\%)\end{array}$ & Initial & Final \\
\hline Lead(Pb) & 508.2 & BDL & $>90$ & 6.3 & 6.1 \\
\hline Manganese(Mn) & 274.9 & 63.57 & 76.87 & 8.4 & 7.9 \\
\hline
\end{tabular}

BDL: Below Detectable Limit

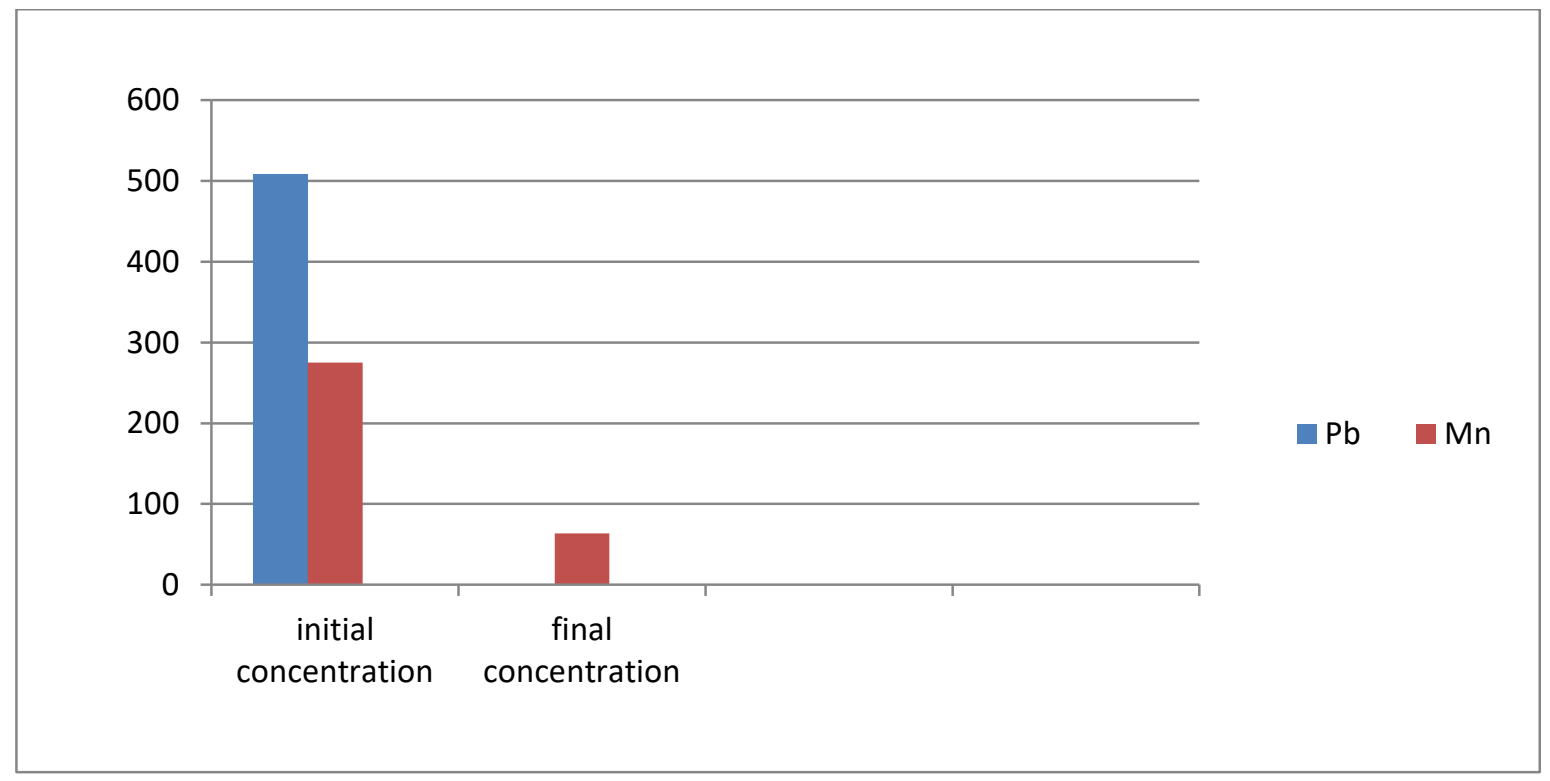

Fig.1: Diagrammatical representation of the Analyzed samples

\section{* CHARACTERISTICS OF THE SAMPLE SOLUTIONS BEFORE PHYCOREMEDIATION}

The concentration of the heavy metals before and after phycoremediation with Spirogyra maxima and percentage of removal efficiency sample metals are presented in Table 1.

The concentrations obtained before phycoremediation of the Lead and Manganese solutions are $508.20 \mathrm{mg} / \mathrm{L}$ and 274.90 respectively. And the initial $\mathrm{pH}$ of the two samples is 6.3 and 8.4 respectively.

\section{* CHARACTERISTICS OF THE SAMPLE SOLUTION AFTER PHYCOREMEDIATION}

The percentage removal efficiency of Manganese was $76.87 \%$ and the percentage removal efficiency of lead is above $90 \%$ is obtained after phycoremediation (30Days). Manganese is associated with catalyze the synthesis of chlorophyll in the aquatic macrophytes. The reduction in the Mn content is in the conformity of their absorption during the phycoremediation experiments. The study led to the conclusion that Spirogyra maxima has high $\mathrm{Pb}$ adsorption capacity which makes it well suited for the removal of $\mathrm{Pb}$ in waste water.

The $\mathrm{pH}$ of the sample solutions was recorded to be alkaline before phycoremediation experiments (Table 1). After phycoremediation (30Days) by using Spirogyra, the value of $\mathrm{pH}$ was decreased 0.2 in Lead solution and 0.5 in Manganese solution. The $\mathrm{pH}$ reduction efficiency of Spirogyra maxima in $\mathrm{Pb}$ solution is $3.17 \%$ and in $\mathrm{Mn}$ solution is $5.95 \%$. 
The cell wall of Algae components will play a crucial role as a defense mechanism in that it is the first barrier to the uptake of toxic metals. This study, on metals uptake by Spirogyra maxima, clearly reveals the efficiency of algae to remove $\mathrm{Pb}$ and $\mathrm{Mn}$ present in the water sources. In the present study, the results proved that Spirogyra maxima has the removal efficiency is more in case of $\mathrm{Pb}$ than the removal efficiency of Mn.

\section{CONCLUSION}

Many researches revealed the contribution of algal biomass for heavy metal removal from waste water. Low cost cultivation and high heavy metal ion uptake capacity, with suitable environmental conditions $(\mathrm{pH}$, temperature, and contact time) make algae biomass as a potential source for waste water bioremediation. Microalgae possess numerous considerable sequestering mechanism heavy metal ions and hence are demarcated as promising biosorbents. Heavy metals are non degradable and must be reduced to acceptable limits before discharging into the environment to avoid threats to living organisms. The present study shows that Spirogyra maxima have substantial ability to remove Lead and Manganese from waste water and hence, they could be recommended for phycoremediation.

The studies from various sources indicated that the use of algae in phycoremediation is very effective and has potential for future applications. Phycoremediation is the most beneficial method as it is a cost effective, easy to handle, less labor work is needed. Produce no hazardous secondary byproducts and residues can be used for biofuel production. So there is a big need to explore this ecofriendly technique to reuse water resources and reduction of water pollution in India.

\section{REFERENCES}

[1] Abdel-Raouf N, Al-Homaidan AA, Ibraheem IBM. Microalgae and waste water treatment. Saudi Journal of Bio. Sci. 2012; 19: 257-275.

[2] Ahalya N, Ramachandra TV, Kanamadi RD (2003) Biosorption of heavy metals. Res J Chem Environ 7:71-78.

[3] Ajayan KV, Selvaraju M, Thirugnanamoorthy K (2011) Growth and heavy metals accumulation potential of microalgae grown in sewage wastewater and Petrochemical Effluents. Pakistan J Biol Sci 14(16):805-811.

[4] Akhtar N, Iqbal M, Zafar SI, Iqbal J (2008) Biosorption characteristics of unicellular green alga Chlorella sorokiniana immobilized in loofa sponge for removal of Cr (III). J Environ Sci 20:231-239.

[5] Ayansina SA, Olubukola OB (2017) A new strategy for heavy metal polluted environments: a reviewofmicrobialbiosorbents.IntJ EnvironRespublicHealth14:94.

[6] Donmez G C, Aksu Z, Ozturk A, Kutsal T (1999), A comparative study on heavy metal biosorption characteristics of some algae. Process Biochem 34:885-892.

[7] Doshi H, Seth C, Ray A, Kothari IL (2008) Bioaccumulation of heavy metals by green algae. Curr Microbiol 56:246-255.

[8] Dwivedi S. (2012). Bioremediation of heavy metal by algae: current and future perspective. J. Adv. Lab. Res. Biol., 3 (3): 195-199.

[9] Elumalai, S., Saravanan, G.K., Ramganesh, S., Sakthivel, R. and Prakasam, V. (2013). Phycoremediation of textile dye industrial effluent from tirupur district, Tamil nadu, India. International Journal of Science Innovations and Discoveries, 3 (1): 31-37.

[10] Gupta.V.K. Shrivastava, A.K. and Neeraj Jain (2001). Biosorption of Chromium (VI) From Aqueous solution by Green Algae Spirogyra species. Water Research, 35(17):40794085.4

[11] Mane PC, Bhosle AB. Bioremoval of Some Metals by Living Algae Spirogyra sps. and Spirullina sps. From aqueous solution, Int. J. Environ. Res., 2012; 6(2):571-576.

[12] Padmapriya, G. and Murugesan, A.G. (2012). Phytoremediation of various heavy metals $(\mathrm{Cu}, \mathrm{Pb}$ and $\mathrm{Hg})$ from aqueous solution using water hyacinth and its toxicity on plants. International Journal of Environmental Biology, 2 (3): 97-103.

[13] Parvathi K, Naresh Kumar R, Nagendran R. Biosorption of Manganese by Aspergillus niger and Saccharomyces cerviciae. World Journal of Microbiology and Biotechnology.2007; 23: 5671-676.

[14] Olguin EJ. Phycoremediation: key issues for cost-effective nutrient removal processes. Biotechnol Advan. 2003; 22(1-2): 81-91.

[15] Yang, X., Wu, X., Hao, H. and He, Z. (2008). Mechanisms and assessment of water eutrophication. J. Zhejiang Univ. Sci. B., 9:197-209. 